\title{
Differences in leaf anatomy, photosynthesis, and photoprotective strategies in the yellow-green leaf mutant and wild type of Rosa beggeriana Schrenk
}

\author{
S.H. YANG*, J.J. WEI ${ }^{*}, *$, F. YAN*, R.D. JIA*, X. ZHAO*, Y. GAN*, and H. GE*,+ \\ National Center of China for Flowers Improvement, Institute of Vegetables and Flowers, Chinese Academy \\ of Agricultural Sciences, 100081 Beijing, China* \\ Beijing Botanic Garden, 100093 Beijing, China**
}

\begin{abstract}
Although the underlying mechanisms of chlorophyll biosynthesis have been intensively deciphered in model plants, leaf color mutants have not yet been fully studied in woody species. In this study, leaf anatomy, diurnal changes in photosynthesis and photoprotection were investigated in the yellow-green leaf $(\mathrm{ygl})$ mutant of Rosa beggeriana. Chloroplast ultrastructure, pigment biosynthesis, and photosynthesis were impaired and led to photoinhibition at noon in the $y g l$ mutant. The negative changes in leaf anatomy increased the risk of excess light absorption in the mutant. Moreover, the $y g l$ mutant preferred to consume the excited energy through photorespiration rather than via heat dissipation. Finally, antioxidant defenses failed to scavenge reactive oxygen species and led to severe lipid peroxidation in the mutant. The results suggested that inhibition of photosynthesis in the $y g l$ mutant of $R$. beggeriana was associated with the altered photoprotective strategies that involved in leaf anatomy, photorespiration, thermal dissipation, and antioxidant system.
\end{abstract}

Keywords: chlorophyll fluorescence; gas exchange; heat dissipation; leaf color mutant; photodamage; rose.

\section{Introduction}

Roses are among the most valuable ornamental crops with over 24,000 registered cultivars all over the world (Young and Schorr 2007). The genus Rosa L. comprises about 200 species, among which only 10-15 species contribute to the genetic make-up of the present cultivars (Bendahmane et al. 2013). Rosa beggeriana Schrenk is an endemic shrub species mainly distributed in Central Asia, including the Xinjiang Uygur Autonomous Region of northwestern China (Gu and Robertson 2003). It has been used as coldresistant germplasm for the interspecific hybridization with modern rose cultivars (Huang et al. 1989, Yang et al. 2016). Recently, a yellow-green leaf ( $y g l$ ) mutant seedling was originated from $R$. beggeriana after the achenes were subjected to ${ }^{60} \mathrm{Co} \gamma$-ray irradiation (Huang et al. 2007). The $y g l$ trait is stably inherited and capable of introgression with another species, namely $R$. davurica Pall. (Yang et al. 2015), which is expected to create the yellow-leaf rose varieties for landscaping. To date, no more leaf color mutant has been reported in genus Rosa L.

Leaf color is typically green when chlorophyll (Chl) predominates in plant leaves. Any defect or blockage in the processes of $\mathrm{Chl}$ biosynthesis may result in the loss of the green color (Bollivar 2006). A great number of Chldeficient mutants have been identified in the model plants and crops, such as Arabidopsis (Wu et al. 2011), rice (Liu et al. 2015), wheat (Falbel et al. 1996), barley (Štroch et al. 2004), maize (Zhong et al. 2015). Furthermore, the underlying molecular mechanisms of leaf color mutations have been deeply studied in Arabidopsis and rice (Reinbothe et al. 2010). However, there are few intensive studies on the Chl-deficient mutants of woody species. The impairment in Chl biosynthesis can disturb the redox balance and evoke the reactive oxygen species (ROS) burst due to less activated $\mathrm{Chl}$ molecules in the thylakoids, eventually leading to membrane damage in Chl-deficient mutants (Bollivar 2006). The abnormal chloroplast ultrastructure and declined photosynthetic performance were observed in the Chl-deficient mutants of some woody

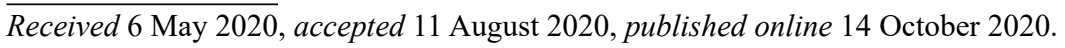

${ }^{+}$Corresponding author; phone/fax: +8610 82109542, e-mail: gehong@caas.cn

Abbreviations: A - antheraxanthin; APX - ascorbate peroxidase; AsA - ascorbate; Chl - chlorophyll; Car - carotenoids; $C_{\mathrm{i}}$ - intercellular $\mathrm{CO}_{2}$ concentration; DEPS - the de-epoxidation state; DHA - dehydroascorbate; ETR - electron transport rate; FM - fresh mass; $\mathrm{F}_{\mathrm{v}} / \mathrm{F}_{\mathrm{m}}-$ maximal quantum yield of PSII photochemistry; $\mathrm{F}_{\mathrm{v}}{ }^{1} / \mathrm{F}_{\mathrm{m}}{ }^{\prime}$ - photochemical efficiency of PSII in the light; GPX - guaiacol peroxidase; $\mathrm{GR}$ - glutathione reductase; $g_{\mathrm{s}}$ - stomatal conductance; GSH - reduced glutathione; GSSG - oxidized glutathione; L - lutein; LE - lower epidermis of the leaves; $L_{\mathrm{s}}$ - stomatal limitation value; MDA - malondialdehyde; $\mathrm{N}$ - neoxanthin; NPQ - nonphotochemical quenching; $P_{\mathrm{N}}-$ net photosynthetic rate; PP - palisade parenchyma; $P_{\mathrm{r}}$ - photorespiration; ROS - reactive oxygen species; $\mathrm{q}_{\mathrm{N}}-$ photochemical quenching; SOD - superoxide dismutase; UE - upper epidermis of the leaves; V - violaxanthin; Z - zeaxanthin; $\Phi_{\mathrm{PSII}}-$ effective quantum yield of PSII photochemistry.

Acknowledgments: This work received grants support from the National Key Research and Development Program of China (2019YFD1000400), the National Natural Science Foundation of China (31672183), and Key Laboratory of Biology and Genetic Improvement of Horticultural Crops, Ministry of Agriculture and Rural Affairs, China.

Conflict of interest: The authors declare that they have no conflict of interest. 
plants including cacao (Rehem et al. 2011), tea (Wang et al. 2014), ginkgo (Liu et al. 2016), and birch (Gang et al. 2019).

Plants have evolved the delicate photoprotective mechanisms to protect the photosynthetic apparatus against oxidative stress (Osmond 1994, Elsheery and Cao 2008). Many studies showed that Chl-deficient mutants tried to improve thermal dissipation by enhancing nonphotochemical quenching (NPQ) and xanthophyll cycle pool for photoprotection (Falbel et al. 1994, Šroch et al. 2004, Zhong et al. 2015, Liu et al. 2016). However, the $y g l$ mutant of foxtail millet preferred to enhance PSII photochemical efficiency rather than dissipate heat to avoid oxidative stress (Li et al. 2016). Besides, the Chldeficient mutant of birch presented the decreased stomatal conductance $\left(g_{\mathrm{s}}\right)$ and unchanged effective quantum yield of PSII photochemistry ( $\Phi_{\text {PSII }}$ ), suggesting avoidance of photoinhibition by stomatal regulation (Gang et al. 2019). The photoprotective mechanisms of leaf color mutants are highly species-dependent. Furthermore, few studies have comprehensively considered the different aspects of the photoprotective strategies, including light absorption, energy partition and dissipation, and ROS scavenging in leaf color mutants.

In the present study, the leaf anatomy, diurnal changes of gas exchange, chlorophyll fluorescence, photosynthetic pigments, and antioxidant systems were investigated between the $y g l$ mutant and wild type (WT) of Rosa beggeriana. We aimed to elucidate the daily changes and differences in photosynthetic performance between the mutant and WT, and further comprehensively explore the photoprotective strategies in the $y g l$ mutant of $R$. beggeriana.

\section{Materials and methods}

Plant material and growth conditions: Ten-year-old WT and $y g l$ mutant plants of $R$. beggeriana were used in this experiment (Fig. 1 $A, B$ ). The $y g l$ mutant was generated from a sprout mutant of $R$. beggeriana in June 2002, the achenes of which had been subjected to ${ }^{60} \mathrm{Co} \gamma$-ray irradiation in the winter of 1998. Previous studies demonstrated that the mutant trait of the yellow-green leaf could be stably inherited by grafting and crossing with the wild type and other species (Huang et al. 2007, Yang et al. 2015). In the summer of 2007, the grafted plants of WT and the $y g l$ mutant of $R$. beggeriana, which possessed the same rootstock from $R$. multiflora Thunb., were planted in the nursery of the Institute of Vegetables and Flowers, Chinese Academy of Agricultural Sciences, Beijing, China $\left(116^{\circ} 19^{\prime} \mathrm{E}, 39^{\circ} 57^{\prime} \mathrm{N}\right)$. The altitude of the experimental field was approximately $50 \mathrm{~m}$ a.s.l., and the mean annual air temperature and rainfall were $12.8^{\circ} \mathrm{C}$ and $584.4 \mathrm{~mm}$, respectively, according to the Beijing Meteorological Station (No. 54511). After ten years of growth, the experiment was conducted on each of five WT and $y g l$ mutant individuals of $R$. beggeriana during August and September 2017.

Electron microscopy and morphometric evaluation:
Rectangular segments $(1 \times 2 \mathrm{~mm})$ excluding the midvein were cut from the top leaflet of fully-opened compound leaves at the top of the current-year branch of the 10-yearold plants at 8:00 h on a sunny day on 17 September 2017 (Fig. 1 $A, B$ ). Five leaflet segments from five individual plants of each genotype were fixed in $2.5 \%$ glutaraldehyde in phosphate-buffered saline $(\mathrm{pH} 7.2)$, dehydrated with an ethanol series, dried to the critical point, and then mounted appropriately on metal stubs for observation of the leaf cross-section and upper and lower epidermis. The leaf samples were further sputtered-coated with gold and then finally observed with a scanning electron microscope (SEM) S450 (Hitachi Ltd., Tokyo, Japan). For transmission electron microscopy (TEM), the leaflet segments were sequentially fixed in $2.5 \%$ glutaraldehyde and $1 \%$ osmium tetroxide in phosphate-buffered saline $(\mathrm{pH}$ 7.2), dehydrated with an ethanol series, and then routinely embedded with resin (EPON). The samples were then cut into ultrathin sections and observed with a TEM H500 (Hitachi Ltd., Tokyo, Japan).

For morphometric evaluation, the leaflet segments were collected from WT and $y g l$ plants for SEM and TEM observations. Three to six valid observation fields per segment were photographed and measured for the parameters of leaf cross-section and upper and lower epidermis for SEM, as well as trichome and stomatal density of the epidermis, cuticle thickness of the upper epidermis, the cytoderm thickness of the upper epidermal cells, numbers of chloroplasts in the mesophyll cell, and for TEM.

Diurnal gas exchange and $\mathrm{Chl}$ fluorescence measurements: The leaflets of the fully-opened compound leaves at the top of current-year branches in each of five WT and $y g l$ plants were chosen for diurnal photosynthesis determination on the same day of leaf anatomy sampling. The day/night air temperature $\left(\mathrm{T}_{\text {air }}\right)$ in the experimental field ranged from 18.2 to $34.6^{\circ} \mathrm{C}$, and VPD varied around 1.1-1.3 $\mathrm{kPa}$. The maximum PPFD exceeded 1,700 $\mu \mathrm{mol}$ $\mathrm{m}^{-2} \mathrm{~s}^{-1}$. Gas exchange was measured with a portable photosynthesis system Li-Cor 6400 (LiCOR Biosciences, Lincoln, NB, USA) from 7:00 to 17:00 h every $2 \mathrm{~h}$. Net photosynthetic rates $\left(P_{\mathrm{N}}\right), g_{\mathrm{s}}$, intercellular $\mathrm{CO}_{2}$ concentration $\left(C_{\mathrm{i}}\right)$, air $\mathrm{CO}_{2}$ concentration $\left(C_{\mathrm{a}}\right)$, and leaf temperature $\left(\mathrm{T}_{\text {leaf }}\right)$ were measured, and stomatal limitation value $\left(L_{\mathrm{s}}\right)$ was calculated as $1-C_{\mathrm{i}} / C_{\mathrm{a}}$ (Farquhar and Sharkey 1982). The photorespiration $\left(P_{\mathrm{r}}\right)$ was estimated based on the different values of the photosynthetic rates between the ambient $(21 \%)$ and low $(2 \%) \mathrm{O}_{2}$ concentrations with $350 \mu \mathrm{mol} \mathrm{mol}{ }^{-1} \mathrm{CO}_{2}$ during the daytime.

Chl fluorescence parameters were measured simultaneously with a portable fluorometer PAM-2100 (Walz, Effeltrich, Germany) on the same individual plants as photosynthesis measurement. After the leaflets were kept in darkness for $30 \mathrm{~min}$, the minimal fluorescence yield of the dark-adapted state $\left(\mathrm{F}_{0}\right)$ was estimated under a low modulated light of $0.6 \mu \mathrm{mol}$ (photon) $\mathrm{m}^{-2} \mathrm{~s}^{-1}$, and the maximal fluorescence yield of the dark-adapted state $\left(\mathrm{F}_{\mathrm{m}}\right)$ was determined using a white light-saturating pulse of $8,000 \mu \mathrm{mol}$ (photon) $\mathrm{m}^{-2} \mathrm{~s}^{-1}$ for $0.8 \mathrm{~s}$. Variable fluorescence 
$\left(\mathrm{F}_{\mathrm{v}}\right)$ was determined as $\mathrm{F}_{\mathrm{m}}-\mathrm{F}_{0}$ and the maximal efficiency of PSII photochemistry $\left(\mathrm{F}_{\mathrm{v}} / \mathrm{F}_{\mathrm{m}}\right)$ was obtained. The leaflet was further exposed to actinic light similar to the ambient PPFD at the measuring time and allowed to stabilize at least $10 \mathrm{~min}$ to reach the steady-state fluorescence yield $\left(\mathrm{F}_{\mathrm{s}}\right)$. Another saturating light pulse of $8,000 \mu \mathrm{mol}$ (photon) $\mathrm{m}^{-2} \mathrm{~s}^{-1}$ was used to measure the maximal fluorescence yield of the light-adapted state $\left(\mathrm{F}_{\mathrm{m}}{ }^{\prime}\right)$, and the minimal fluorescence of the light-adapted state $\left(\mathrm{F}_{0}{ }^{\prime}\right)$ was obtained in the presence of infrared light at $15 \mu \mathrm{mol}$ (photon) $\mathrm{m}^{-2} \mathrm{~s}^{-1}$. $\Phi_{\text {PSII }}$, photochemical efficiency of PSII in the light $\left(\mathrm{F}_{\mathrm{v}}{ }^{\prime} / \mathrm{F}_{\mathrm{m}}{ }^{\prime}\right)$, and NPQ were calculated in 2-h intervals, from 7:00 to $17: 00 \mathrm{~h}$, according to the formulas: $\left(\mathrm{F}_{\mathrm{m}}{ }^{\prime}-\mathrm{F}_{\mathrm{s}}\right) / \mathrm{F}_{\mathrm{m}}{ }^{\prime}$, $\left(F_{m}{ }^{\prime}-F_{s}\right) /\left(F_{m}{ }^{\prime}-F_{0}{ }^{\prime}\right)$, and $\left(F_{m} / F_{m}{ }^{\prime}\right)-1$, respectively. The relative PSII-driven electron transport rate (ETR) was calculated as $\Phi_{\text {PSII }} \times$ PPFD $\times 0.5$ (Genty et al. 1989, Demmig-Adams 2003, Elsheery et al. 2007). After each 2-h interval measurement, the leaflets were sampled as leaf discs with $1 \mathrm{~cm}^{2}$ in size, then frozen in liquid nitrogen and stored at $-80^{\circ} \mathrm{C}$.

Pigment analysis: The frozen leaflets from three individual plants of each genotype were applied for photosynthetic pigment analysis. Five leaf discs (total of $5 \mathrm{~cm}^{2}$ ) as one replicate were extracted in ice-cold $100 \%$ acetone, following which the extracts were filtered through a $0.2-\mu \mathrm{m}$ syringe filter into a vial for high-performance liquid chromatography (HPLC) analysis. An HPLC system Alliance e2695 (Waters Corporation, Milford, MA, USA) was used for pigment analysis according to Thayer and Björkman (1990), with some modifications. A C18 column $(250 \times 4.6 \mathrm{~mm}$ I. D., $5 \mu \mathrm{m}$ particle size $)$ was used in the separation. The pigments were eluted

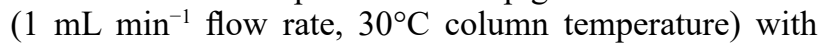
$100 \%$ solvent A (acetonitrile:methanol $=15: 85, \mathrm{v} / \mathrm{v}$ ) for the first $14.5 \mathrm{~min}$ followed by a 3-min linear gradient to solvent B (acetonitrile:ethyl acetate $=68: 32$, v/v), which continued isocratically until $28 \mathrm{~min}$. The column was reequilibrated in solvent $A$ for $10 \mathrm{~min}$ before the next injection. The eluted pigments including different Chl and carotenoids (Car) were monitored at $440 \mathrm{~nm}$ with a diode array detector and quantified using the sequential pigment standards (HPLC grade, Sigma-Aldrich, St. Louis, Missouri, USA) of neoxanthin (N), violaxanthin $(\mathrm{V})$, antheraxanthin (A), lutein (L), zeaxanthin (Z), Chl $a$, $\mathrm{Chl} b$, and $\beta$-carotene.

Hydrogen peroxide and lipid peroxidation measurements: Hydrogen peroxide $\left(\mathrm{H}_{2} \mathrm{O}_{2}\right)$ was measured based on the reaction of potassium iodide (KI) deoxidization as described by Alexieva et al. (2001). Frozen leaflets from five individual plants of each genotype were extracted in an ice bath with $0.1 \%(\mathrm{w} / \mathrm{v})$ trichloroacetic acid (TCA) and then reacted with $1 \mathrm{M}$ KI in potassium phosphate buffer ( $\mathrm{pH}$ 7.0) for $1 \mathrm{~h}$ in the dark. The absorbance was measured at $390 \mathrm{~nm}$ (Specord 200, Analytik Jena AG, Jena, Germany), and the $\mathrm{H}_{2} \mathrm{O}_{2}$ concentration was determined using a prepared standard curve.

Lipid peroxidation was estimated based on malondialdehyde (MDA) content using the thiobarbituric acid
(TBA) reaction according to the method of Heath and Packer (1968). Frozen leaflets from five individual plants of each genotype were extracted in ice-cold $0.1 \%(\mathrm{w} / \mathrm{v})$ TCA and mixed with $20 \%$ TCA containing $0.5 \%(\mathrm{w} / \mathrm{v})$ TBA, following which they were heated in boiling water. The quantity of MDA was calculated from the difference in absorbance at 532 and $600 \mathrm{~nm}$ using the extinction coefficient of $1.55 \mathrm{mM}^{-1} \mathrm{~cm}^{-1}$ (Specord 200, Analytik Jena $A G$, Jena, Germany).

Antioxidant enzyme assays: Frozen leaflets from five individual plants of each genotype were extracted in $50 \mathrm{mM}$ potassium phosphate buffer $(\mathrm{pH} 7.0)$ containing $0.1 \mathrm{mM}$ EDTA and $1 \%(\mathrm{w} / \mathrm{v})$ polyvinylpolypyrrolidone (PVPP) for measuring the activities of superoxide dismutase (SOD, EC 1.15.1.1) and guaiacol peroxidase (GPX, EC 1.11.1.7). For the determination of ascorbate peroxidase (APX, EC 1.11.1.11) and glutathione reductase (GR, EC 1.6.4.2), the leaflets were homogenized in $50 \mathrm{mM}$ Tris- $\mathrm{HCl}(\mathrm{pH} 7.0)$ containing $20 \%(\mathrm{w} / \mathrm{v})$ glycerol, $1 \mathrm{mM}$ reduced glutathione $(\mathrm{GSH})$, and $5 \mathrm{mM} \mathrm{MgCl}_{2}$. The enzyme activities of SOD, catalase (CAT, EC 1.11.1.6), GPX, APX, and GR were measured using a spectrophotometer Specord 200 (Analytik Jena AG, Jena, Germany) according to the methods of Yang et al. (2007). Total soluble protein was determined by the method of Bradford (1976) using bovine serum albumin as a standard.

Ascorbate and glutathione determination: Frozen leaves from five individual plants of each genotype were extracted in $5 \%(\mathrm{w} / \mathrm{v})$ metaphosphoric acid for ascorbate and glutathione measurement according to the method of Anderson et al. (1992). To determine total ascorbate, the supernatant was reacted with dithiothreitol (DTT) for the reduction of dehydroascorbate (DHA) to ascorbate (AsA) and then sequentially mixed with $0.5 \mathrm{M} \mathrm{N}$-ethylmaleimide (NEM) in EDTA and phosphate buffer (pH 7.4), 10\% (w/v) TCA, 44\% (v/v) orthophosphoric acid, 4\% (w/v) 2,2'-dipyridyl in $70 \%$ ethanol, and $3 \%(\mathrm{w} / \mathrm{v}) \mathrm{FeCl}_{3}$, and then incubated at $37^{\circ} \mathrm{C}$ for $1 \mathrm{~h}$. The amount of total ascorbate was calculated from the difference in absorbance at $525 \mathrm{~nm}$ with the standard curve of AsA (Specord 200, Analytik Jena AG, Jena, Germany). The AsA was measured using the same procedure, except DTT and NEM were substituted with $\mathrm{H}_{2} \mathrm{O}$.

The concentrations of GSH and oxidized (GSSG) glutathione were determined spectrophotometrically at $412 \mathrm{~nm}$ (Specord 200, Analytik Jena AG, Jena, Germany). The enzyme-recycling assay was based on the sequential oxidation of glutathione by 5,5'-dithiobis-(2-nitrobenzoic acid) (DTNB) and reduction by NADPH in the presence of standard glutathione reductase (GR). To quantify the quantity of GSSG, 2-vinyl pyridine was added to the extract. Standard curves were generated with the standards GSH and GSSG.

Statistical analysis: Statistical analysis was performed using SPSS 13.0 software for Windows (SPSS Inc., Chicago, IL, USA). Independent-sample $t$-test and analysis of variance $(A N O V A)$ were applied after the data were 
checked for normality of distribution and the homogeneity of variances. The variables were log-transformed when necessary to improve the normality of residuals. Duncan's multiple comparisons were used for assessing significance among the different time intervals and genotypes. Plots and tables were drawn using SigmaPlot 10.0 (SPSS Inc., Chicago, IL, USA) and Microsoft Excel 2000 (Microsoft Corporation, Redmond, WA, USA). Data are mean \pm SE in the figures and tables.

\section{Results}

Leaf anatomy: Leaf anatomic structures, including the epidermis and mesophyll, was well-shaped in both the WT and $y g l$ mutant (Fig. 1C,D). However, the leaf thickness was significantly lower in the $y g l$ plants than that in the WT (Table 1). The trichome density of the upper (UE) and lower (LE) epidermis was similar in the WT (Fig. 1E, $G$; Table 1). In contrast, trichomes were hardly observed on the
UE and very few on the LE of the $y g l$ mutants (Fig. $1 F, H$ ). The hair densities of UE and LE were thus significantly lower in the $y g l$ plants than that in WT (Table 1). In both genotypes, stomata were not observed in UE but were frequently distributed in LE (Fig. $1 E-H$ ). The stomatal density was significantly lower in the LE of the $y g l$ mutants than that in WT (Table 1).

The cuticle of UE was significantly thinner in the $y g l$ mutant than that in WT. Moreover, the cytoderm thickness of the UE cells was significantly lower in the $y g l$ plants than that in WT (Fig. 2A,B; Table 1). The palisade parenchyma (PP) cells generally presented as long oblong cells in the mesophyll of the WT, but were ovoid or elliptical in the $y g l$ mutant (Fig. 2C,D), leading to smaller PP cells in the $y g l$ plants (Table 1). The chloroplast density was also significantly lower in the PP cells of the $y g l$ mutant than in WT. However, the cell shapes and sizes, as well as the chloroplast numbers in the spongy parenchyma (SP), did not differ between the genotypes (Fig. 2E,F; Table 1). The
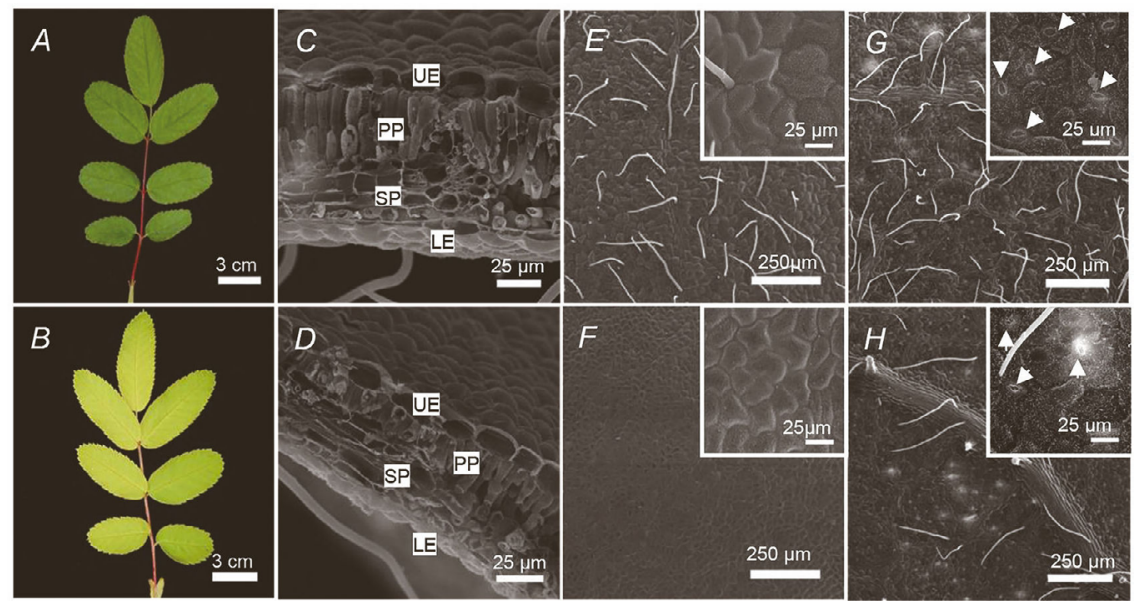

Fig. 1. Leaf phenotypes $(A, B)$, and scanning electron micrographs of crosssections $(C, D)$, the upper epidermis (UE) $(E, F)$, and the lower epidermis (LE) $(G, H)$ of WT and the $y g l$ mutant of Rosa beggeriana. The arrows show the stomata. PP - palisade parenchyma; $\mathrm{SP}$ - spongy parenchyma.

Table 1. The statistics in leaf anatomy of wild type (WT) and the yellow-green leaf $(y g l)$ mutant of Rosa beggeriana. Values are means \pm SE with 10-20 biological replicates of the leaves and unrepeated micrographic fields. In each column, means with one (*) or two (**) asterisks indicate the significant differences between WT and $y g l$ mutant at $P<0.05$ and $P<0.01$, respectively. UE - upper epidermis; LE - lower epidermis; PP - palisade parenchyma; SP - spongy parenchyma; OGs - osmiophilic globules.

\begin{tabular}{|c|c|c|c|}
\hline \multicolumn{2}{|c|}{ Rosa beggeriana } & WT & $y g l$ \\
\hline \multicolumn{2}{|c|}{ Leaf thickness $[\mu \mathrm{m}]$} & $114.1 \pm 1.7$ & $86.9 \pm 0.9^{* *}$ \\
\hline \multicolumn{2}{|c|}{ Trichome density of UE $\left[\mathrm{mm}^{-2}\right]$} & $49.3 \pm 2.4$ & $2.2 \pm 0.9^{* *}$ \\
\hline \multicolumn{2}{|c|}{ Trichome density of LE $\left[\mathrm{mm}^{-2}\right]$} & $58.4 \pm 2.6$ & $20.9 \pm 3.6^{* *}$ \\
\hline \multicolumn{2}{|c|}{ Stomata density of LE $\left[\mathrm{mm}^{-2}\right]$} & $139.9 \pm 11.3$ & $106.7 \pm 7.2^{*}$ \\
\hline \multicolumn{2}{|c|}{ Cytoderm thickness of UE cell $[\mu \mathrm{m}]$} & $1.68 \pm 0.02$ & $1.16 \pm 0.02^{*}$ \\
\hline \multicolumn{2}{|c|}{ Cuticular thickness of UE $[\mathrm{nm}]$} & $138.6 \pm 8.7$ & $117.4 \pm 4.6^{*}$ \\
\hline \multirow[t]{4}{*}{ PP cells } & Length $[\mu \mathrm{m}]$ & $18.66 \pm 0.44$ & $9.84 \pm 0.38^{*}$ \\
\hline & Width $[\mu \mathrm{m}]$ & $7.18 \pm 0.35$ & $6.43 \pm 0.10^{*}$ \\
\hline & Numbers of chloroplast per cell & $7.4 \pm 0.1$ & $4.5 \pm 0.3^{* *}$ \\
\hline & Numbers of OGs per chloroplast & $3.9 \pm 0.2$ & $4.8 \pm 0.3^{* *}$ \\
\hline \multirow[t]{4}{*}{ SP cells } & Length $[\mu \mathrm{m}]$ & $9.71 \pm 0.43$ & $9.65 \pm 0.33$ \\
\hline & Width $[\mu \mathrm{m}]$ & $8.19 \pm 0.44$ & $7.62 \pm 0.44$ \\
\hline & Numbers of chloroplast per cell & $4.5 \pm 0.2$ & $4.2 \pm 0.1$ \\
\hline & Numbers of OGs per chloroplast & $3.2 \pm 0.3$ & $5.6 \pm 0.4^{* *}$ \\
\hline
\end{tabular}




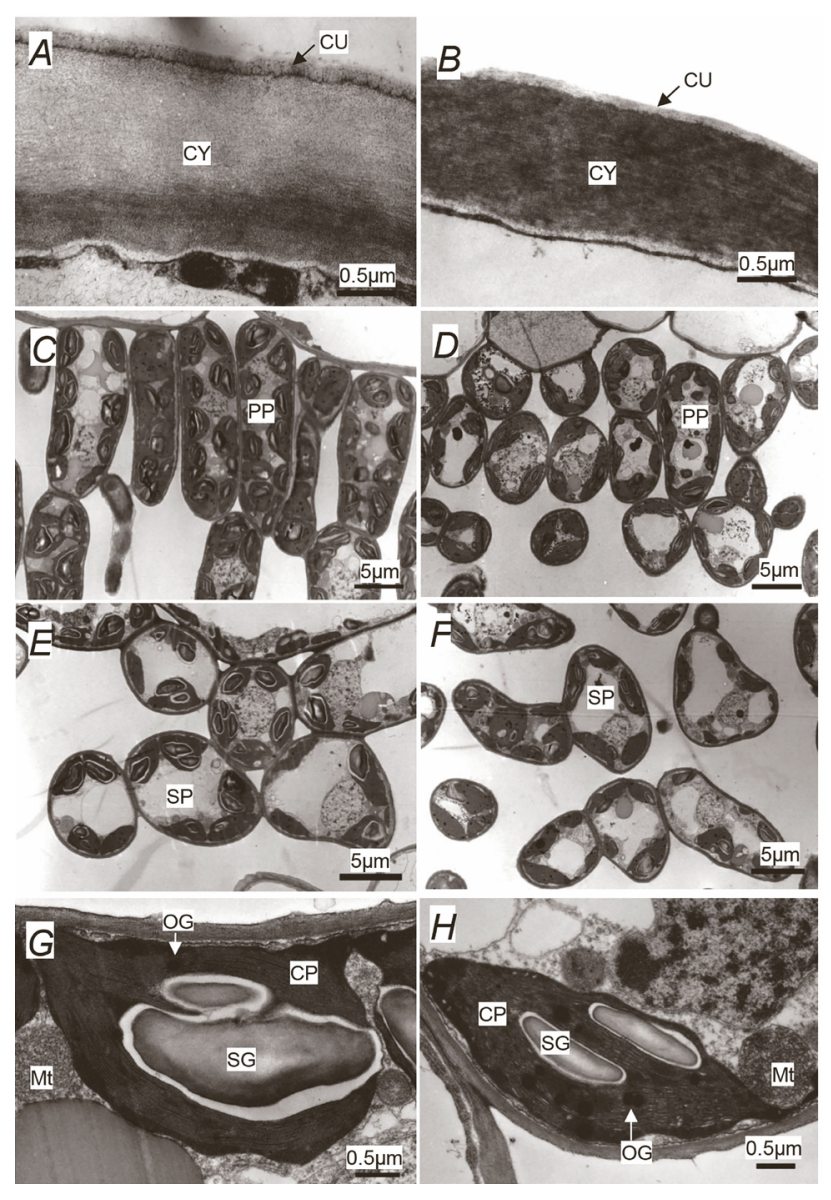

Fig. 2. Leaf transmission electron micrographs of upper epidermis $(A, B)$, the palisade parenchyma (PP) of the mesophyll cells $(C, D)$, and the spongy parenchyma (SP) of the mesophyll cells $(G, H)$ of WT and the $y g l$ mutant of Rosa beggeriana. CU - cutin of the upper epidermis; $\mathrm{CY}$ - cytoderm of the upper epidermal cells; $\mathrm{CP}$ - chloroplast of the mesophyll cell; $\mathrm{SG}$ - starch granule; $\mathrm{OG}-$ osmiophilic globule; $\mathrm{Mt}$ - mitochondria of the mesophyll cell.

mitochondria and chloroplasts were intact in the PP cells of the WT and the $y g l$ mutant (Fig. $2 G, H$ ). Thylakoids and starch granules filled the chloroplasts in both genotypes. However, the thylakoids were slightly swollen with fewer grana and increased osmiophilic globules (OGs) in chloroplasts of the mutant in comparison to WT, which possessed chloroplasts with well-arranged thylakoids. Significantly higher OGs numbers per chloroplast were observed in both PP and SP cells (Table 1).

Diurnal gas exchange: $P_{\mathrm{N}}$ peaked at 9:00 h, sharply declining thereafter until 17:00 h (Fig. 3A). There were significantly lower $P_{\mathrm{N}}$ values in the $y g l$ plants than that in WT during the daytime. A similar trend was observed in $g_{\mathrm{s}}$, except that the mutant and WT only differed significantly before 11:00 h (Fig. $3 B$ ). $C_{\mathrm{i}}$ was significantly lower in WT from 11:00 to 15:00 h, recovering thereafter (Fig. 3C). An increase in $P_{\mathrm{r}}$ was observed from 7:00 to $11: 00 \mathrm{~h}$ in both genotypes and declined from 13:00 to $17: 00 \mathrm{~h}$ (Fig. $3 D$ ). The ratios of $P_{\mathrm{r}} / P_{\mathrm{N}}$ varied during the daytime, while significantly higher $P_{\mathrm{r}}$ values and $P_{\mathrm{r}} / P_{\mathrm{N}}$ ratios exhibited at 13:00 and 15:00 $\mathrm{h}$ in the $y g l$ mutant than in WT. The leaf temperatures $\left(\mathrm{T}_{\text {leaf }}\right)$ were lower than $\mathrm{T}_{\text {air }}$ during the daytime and significantly higher at 11:00 and 13:00 $\mathrm{h}$ in the $y g l$ plants than that in WT (Fig. $3 E$ ). $L_{\mathrm{s}}$ was significantly higher at 11:00 and 13:00 h in WT and slowly decreased thereafter but declined slowly in the $y g l$ mutant throughout the day (Fig. $3 F$ ).

Diurnal Chl fluorescence: The $\mathrm{F}_{0}$ values in the $y g l$ mutant were higher than that in WT at 7:00 and 13:00 h (Fig. 4A). $\mathrm{F}_{0}$ did not change from 7:00 to $13: 00 \mathrm{~h}$ in WT, whereas there was a significant increase in the $y g l$ mutant at 13:00 h. $\mathrm{F}_{\mathrm{v}} / \mathrm{F}_{\mathrm{m}}$ was similar at 7:00 $\mathrm{h}$ in both genotypes and then significantly decreased at $13: 00 \mathrm{~h}$ in the $y g l$ plants (Fig. $4 B$ ). The diurnal $\Phi_{\mathrm{PSII}}$ and $\mathrm{F}_{\mathrm{v}}{ }^{\prime} / \mathrm{F}_{\mathrm{m}}{ }^{\prime}$ decreased in both genotypes until noon and then rapidly recovered before dusk (Fig. $5 A, B)$. There were significantly lower $\Phi_{\text {PSII }}$ and $\mathrm{F}_{\mathrm{v}}{ }^{\prime} / \mathrm{F}_{\mathrm{m}}{ }^{\prime}$ values at 11:00 and 13:00 $\mathrm{h}$ in the $y g l$ mutant than in WT. In contrast, ETR peaked at 11:00 $\mathrm{h}$ in the $y g l$ plants and 13:00 $\mathrm{h}$ in WT (Fig. 5C), and significantly lower ETR values were observed at 11:00 and 13:00 $\mathrm{h}$ in the mutant. Besides, NPQ peaked at 13:00 $\mathrm{h}$ in both genotypes and was significantly lower in the $y g l$ plants than that in WT from 9:00 to 15:00 h (Fig. 5D).

Pigment pools: The total $\mathrm{Chl}$ and $\mathrm{Car}$ contents were significantly lower in the $y g l$ plants than that in WT at both 7:00 and 13:00 $\mathrm{h}$ (Table 2), suggesting reduced pigment pools in the $y g l$ mutant of $R$. beggeriana. However, the ratios of Chl $a$ to $\mathrm{Chl} b(\mathrm{Chl} a / b)$ and the total Car to $\mathrm{Chl}$ [Car/Chl $(a+b)]$ were higher in the $y g l$ plants than that in WT at 7:00 and 13:00 h. Most of the pigments, except A and $\mathrm{Z}$, decreased from 7:00 to 13:00 $\mathrm{h}$ in both genotypes and exhibited the lower contents only in WT but not in the $y g l$ plants. A and $\mathrm{Z}$ were not detected at 7:00 h but increased at 13:00 $\mathrm{h}$ in both genotypes. Interestingly, the total xanthophyll cycle pool $(\mathrm{V}+\mathrm{A}+\mathrm{Z})$ was unaltered from 7:00 to 13:00 $\mathrm{h}$, resulting in increased ratios of $(\mathrm{V}+\mathrm{A}+\mathrm{Z})$ to $\mathrm{Chl}(a+b)$ in the two genotypes. DEPS was not detected at 7:00 $\mathrm{h}$ and was quite low at 13:00 $\mathrm{h}$ in both genotypes. DEPS did not differ between the two genotypes.

Diurnal hydrogen peroxide and lipid peroxidation: $\mathrm{H}_{2} \mathrm{O}_{2}$ contents did not change significantly in WT during the daytime but increased from 7:00 to 11:00 $\mathrm{h}$ and then declined until 17:00 h in the $y g l$ plants (Fig. 6A). The $\mathrm{H}_{2} \mathrm{O}_{2}$ contents were significantly higher in the mutant than that in WT. MDA content exhibited a very similar trend as $\mathrm{H}_{2} \mathrm{O}_{2}$ content in both genotypes (Fig. $6 B$ ), though significantly higher MDA contents were observed from 9:00 to 13:00 h in the mutant.

Diurnal activities of antioxidant enzymes: There was also no significant difference in SOD and GR activity between two genotypes, except that higher GR activity was detected at 9:00 $\mathrm{h}$ in the $y g l$ plants (Fig. $6 C, F$ ). GPX activity differed significantly between the two genotypes from 7:00 to 11:00 h, peaking at 9:00 h in $y g l$ and 13:00 h in WT and both declining until 17:00 $\mathrm{h}$ following the peak 

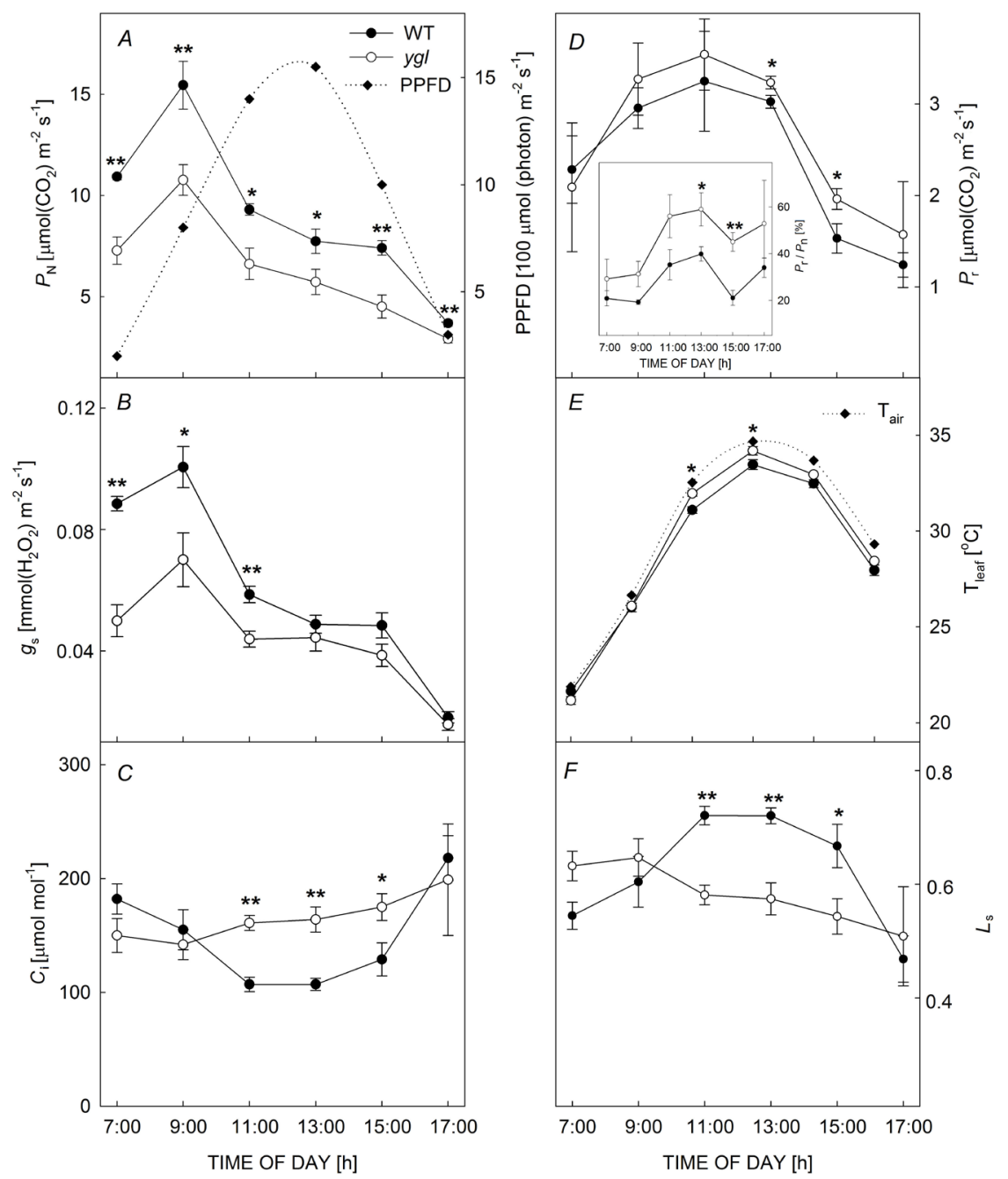

Fig. 3. The diurnal variations in net photosynthesis $\left(P_{\mathrm{N}}\right)$ and photosynthetic photon flux density (PPFD) $(A)$, stomatal conductance $\left(g_{s}\right)(B)$, intercellular $\mathrm{CO}_{2}$ concentration $\left(C_{\mathrm{i}}\right)(C)$, photorespiration rate $\left(P_{\mathrm{r}}\right)(D)$, air temperatures $\left(\mathrm{T}_{\text {air }}\right)$ and leaf temperatures $\left(\mathrm{T}_{\text {leaf }}\right)(E)$, and stomatal limitation value $\left(L_{\mathrm{s}}\right)(F)$ of WT and the $y g l$ mutant of Rosa beggeriana. Values are means \pm SE with five biological replicates. Means with one $(*)$ or two $(* *)$ asterisks indicate the significant differences between WT and $y g l$ mutant at $P<0.05$ and $P<0.01$, respectively.

(Fig. 6D). APX activity was significantly higher at 9:00 and 11:00 $\mathrm{h}$ in $y g l$ (Fig. 6E).

Diurnal ascorbate and glutathione pools: Lower average AsA contents were observed in the $y g l$ mutants than that in WT during the daytime, except at 15:00 h, although the differences were not statistically significant (Fig. $7 A$ ). DHA contents decreased in WT, while the mutant demonstrated a sharp and significant increase in DHA from 11:00 to 17:00 h (Fig. 7B). As a consequence, WT exhibited higher ratios of AsA/DHA than the mutant, differing significantly at 9:00, 13:00, and 17:00 h (Fig. 7C). There were lower average GSH and GSSG values in WT than the mutant during most of the day, though the only significant value was observed at 11:00 $\mathrm{h}$ in GSH content (Fig. 7D,E). As a result, the ratios of GSH/GSSG did not differ significantly between the two genotypes (Fig. $7 F$ ).

\section{Discussion}

Leaf color mutants are common in plants that usually exhibited impaired Chl biosynthesis, chloroplast development, and photosynthesis. In the present study, the pigments including $\mathrm{Chl}$ and Car were significantly lower in the leaves of $y g l$ mutant than that in WT of $R$. beggeriana (Table 2), indicating there were lower leaf photosynthetic pigment pools in the mutant than that in wild type. Interestingly, leaf pigment pools decreased from dawn to noon in both genotypes and exhibited the endogenous circadian rhythms in the pigment compositions, which was in accordance with the previous study on bean and cotton (García-Plazaola et al. 2017). On the other hand, the mutant also exhibited undesirable changes with fewer numbers of chloroplasts, and abnormal thylakoids in the PP cells of the leaves (Fig. 2). Moreover, the dramatic changes in leaf anatomy of the mutant, not likely as the limited anatomical variation in one genotype (Flexas et al. 2018, Carriquí et al. 2019), might affect the mesophyll $\mathrm{CO}_{2}$ diffusion and further influence photosynthetic performance. These results confirmed that there were significant changes in chloroplast ultrastructure and photosynthetic pigment pools in the $y g l$ mutant, likely as other woody plants (Rehem et al. 2011, Wang et al. 2014, Liu et al. 2016, Gang et al. 2019).

$P_{\mathrm{N}}$ continuously decreased from 9:00 $\mathrm{h}$ in both genotypes and showed significantly lower values in the 
$y g l$ mutant than that in WT throughout the measuring day (Fig. 3A), suggesting that photosynthesis was impaired in both genotypes and there was a severer decline of

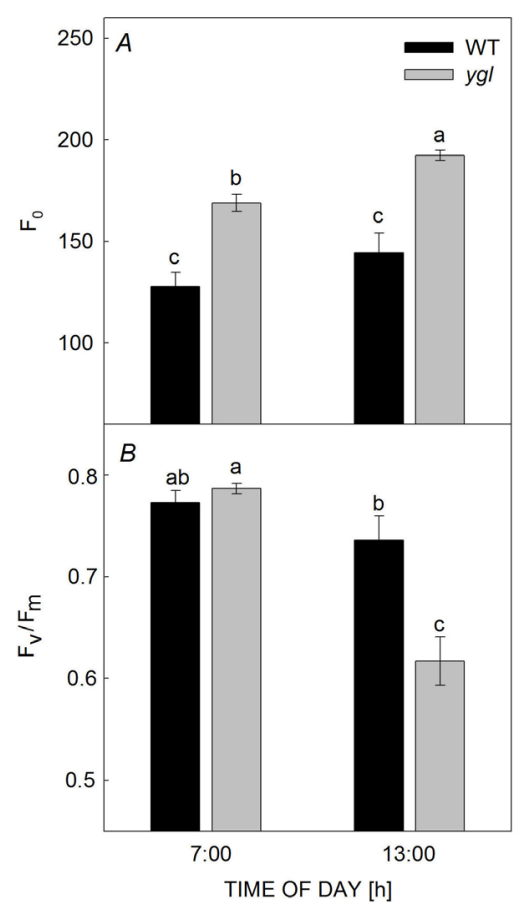

Fig. 4. The variations in the minimal fluorescence $\left(\mathrm{F}_{0}\right)(A)$ and the maximal efficiency of PSII photochemistry $\left(\mathrm{F}_{\mathrm{v}} / \mathrm{F}_{\mathrm{m}}\right)(B)$ of WT and the $y g l$ mutant of Rosa beggeriana at 7:00 and 13:00 h. Values are means \pm SE with four biological replicates. Means followed by different letters indicate significant differences among the columns at $P<0.05$. photosynthesis in the mutant than that in WT. In general, reduced $P_{\mathrm{N}}$ in higher plants can result from stomatal or nonstomatal limitations. The stomatal limitation in $P_{\mathrm{N}}$ takes place only when $C_{\mathrm{i}}$ decreases together with increased $L_{\mathrm{S}}$ value (Farquhar and Sharkey 1982). In this study, significantly lower $C_{\mathrm{i}}$ values and increased $L_{\mathrm{S}}$ values were observed at noon in WT in comparison to the morning, but $C_{\mathrm{i}}$ and $L_{\mathrm{S}}$ did not significantly alter in the $y g l$ mutant during the daytime (Fig. $3 C, F$ ). The results indicated that the midday decline in $P_{\mathrm{N}}$ in WT and the mutant should be due to stomatal limitation and nonstomatal limitation, respectively.

$\mathrm{F}_{\mathrm{v}} / \mathrm{F}_{\mathrm{m}}$ is a reliable indicator of potential PSII photochemistry, in which a sustained decrease in $F_{v} / F_{m}$ and an increase in $F_{0}$ may reflect the occurrence of photoinhibition in response to different stresses (Foyer and Noctor 2000). Considering the decreased pigment pools in the leaves, it is much more frequent for leaf color mutants than for wild types to encounter excess light stress. $F_{v} / F_{m}$ was previously found to be significantly lower in the leafcolor mutants of barley (Štroch et al. 2004), cacao (Rehem et al. 2011), and maize (Zhong et al. 2015), but higher in the mutant of ginkgo (Liu et al. 2016). In our results, $\mathrm{F}_{0}$ and $\mathrm{F}_{\mathrm{v}} / \mathrm{F}_{\mathrm{m}}$ values did not change in the morning and at noon in WT (Fig. 4). However, $F_{0}$ increased and $F_{v} / F_{m}$ decreased at noon in the $y g l$ mutant in comparison to the morning, which suggests that photoinhibition occurred at midday in the mutant.

Plants have developed several photoprotective strategies to protect the leaves against oxidative stress, thus efficiently balancing light capture and utilization (Osmond 1994). Leaf anatomical features, such as leaf thickness, a waxy cuticle, and epidermal trichome density, can function as the first barriers to intercept excess light into chloroplasts (Filella and Peñuelas 1999, Riederer and

Table 2. The variations in pigment pools in the wild type (WT) and yellow-green leaf $(y g l)$ mutant of Rosa beggeriana at 7:00 and 13:00 $\mathrm{h}$. DEPS - the de-epoxidation state denoted as $(1 / 2 \mathrm{~A}+\mathrm{Z}) /(\mathrm{V}+\mathrm{A}+\mathrm{Z})$. n.a. - not available, n.d. - undetected. Values are means $\pm \mathrm{SE}$ with three biological replicates. In each column, means followed by different letters indicate significant differences at $P<0.05$.

\begin{tabular}{lllll}
\hline Pigments $\left[\mu \mathrm{mol} \mathrm{m}{ }^{-2}\right]$ & $7: 00 \mathrm{~h}$ & & $13: 00 \mathrm{~h}$ & \\
& WT & $y g l$ & WT & $y g l$ \\
\hline Chl $a$ & $698.2 \pm 74.24^{\mathrm{a}}$ & $79.5 \pm 7.7^{\mathrm{c}}$ & $397.5 \pm 83.5^{\mathrm{b}}$ & $47.8 \pm 3.7^{\mathrm{c}}$ \\
Chl $b$ & $244.2 \pm 30.0^{\mathrm{a}}$ & $20.3 \pm 1.3^{\mathrm{c}}$ & $135.1 \pm 26.3^{\mathrm{b}}$ & $11.0 \pm 0.6^{\mathrm{c}}$ \\
Chl $(a+b)$ & $942.4 \pm 103.6^{\mathrm{a}}$ & $99.8 \pm 8.6^{\mathrm{c}}$ & $532.6 \pm 109.8^{\mathrm{b}}$ & $58.7 \pm 4.2^{\mathrm{c}}$ \\
Chl $a / b$ & $2.87 \pm 0.09^{\mathrm{b}}$ & $3.91 \pm 0.32^{\mathrm{a}}$ & $2.93 \pm 0.05^{\mathrm{b}}$ & $4.36 \pm 0.20^{\mathrm{a}}$ \\
$\beta$-carotene & $39.1 \pm 7.5^{\mathrm{a}}$ & $25.4 \pm 7.8^{\mathrm{ab}}$ & $12.6 \pm 4.2^{\mathrm{b}}$ & $13.7 \pm 2.6^{\mathrm{b}}$ \\
Lutein & $137.2 \pm 14.3^{\mathrm{a}}$ & $36.6 \pm 1.9^{\mathrm{c}}$ & $108.3 \pm 13.6^{\mathrm{b}}$ & $32.0 \pm 2.0^{\mathrm{c}}$ \\
Neoxanthin & $66.4 \pm 5.5^{\mathrm{a}}$ & $13.0 \pm 2.5^{\mathrm{c}}$ & $45.6 \pm 7.0^{\mathrm{b}}$ & $6.5 \pm 0.3^{\mathrm{c}}$ \\
Violaxanthin $(\mathrm{V})$ & $62.0 \pm 6.2^{\mathrm{a}}$ & $21.0 \pm 3.4^{\mathrm{c}}$ & $41.9 \pm 9.6^{\mathrm{b}}$ & $12.2 \pm 1.3^{\mathrm{c}}$ \\
Antheraxanthin $(\mathrm{A})$ & n.d. & n.d. & $9.3 \pm 2.7^{\mathrm{a}}$ & $4.5 \pm 1.3^{\mathrm{a}}$ \\
Zeaxanthin $(\mathrm{Z})$ & n.d. & n.d. & $10.8 \pm 7.2^{\mathrm{a}}$ & $6.2 \pm 2.8^{\mathrm{a}}$ \\
Total Car & $304.7 \pm 31.7^{\mathrm{a}}$ & $96.0 \pm 12.0^{\mathrm{c}}$ & $228.3 \pm 23.1^{\mathrm{b}}$ & $75.1 \pm 2.2^{\mathrm{c}}$ \\
Car/Chl $(a+b)$ & $0.32 \pm 0.01^{\mathrm{b}}$ & $0.98 \pm 0.20^{\mathrm{a}}$ & $0.47 \pm 0.16^{\mathrm{b}}$ & $1.29 \pm 0.13^{\mathrm{a}}$ \\
V+A+Z & $62.0 \pm 6.2^{\mathrm{a}}$ & $21.0 \pm 3.4^{\mathrm{b}}$ & $62.0 \pm 8.4^{\mathrm{a}}$ & $22.9 \pm 2.9^{\mathrm{b}}$ \\
$(\mathrm{V}+\mathrm{A}+Z) / C h l(a+b)$ & $0.07 \pm 0.01^{\mathrm{c}}$ & $0.22 \pm 0.05^{\mathrm{b}}$ & $0.13 \pm 0.04^{\mathrm{ab}}$ & $0.40 \pm 0.07^{\mathrm{a}}$ \\
DEPS & n.a. & n.a. & $0.12 \pm 0.06^{\mathrm{a}}$ & $0.17 \pm 0.06^{\mathrm{a}}$ \\
\hline
\end{tabular}



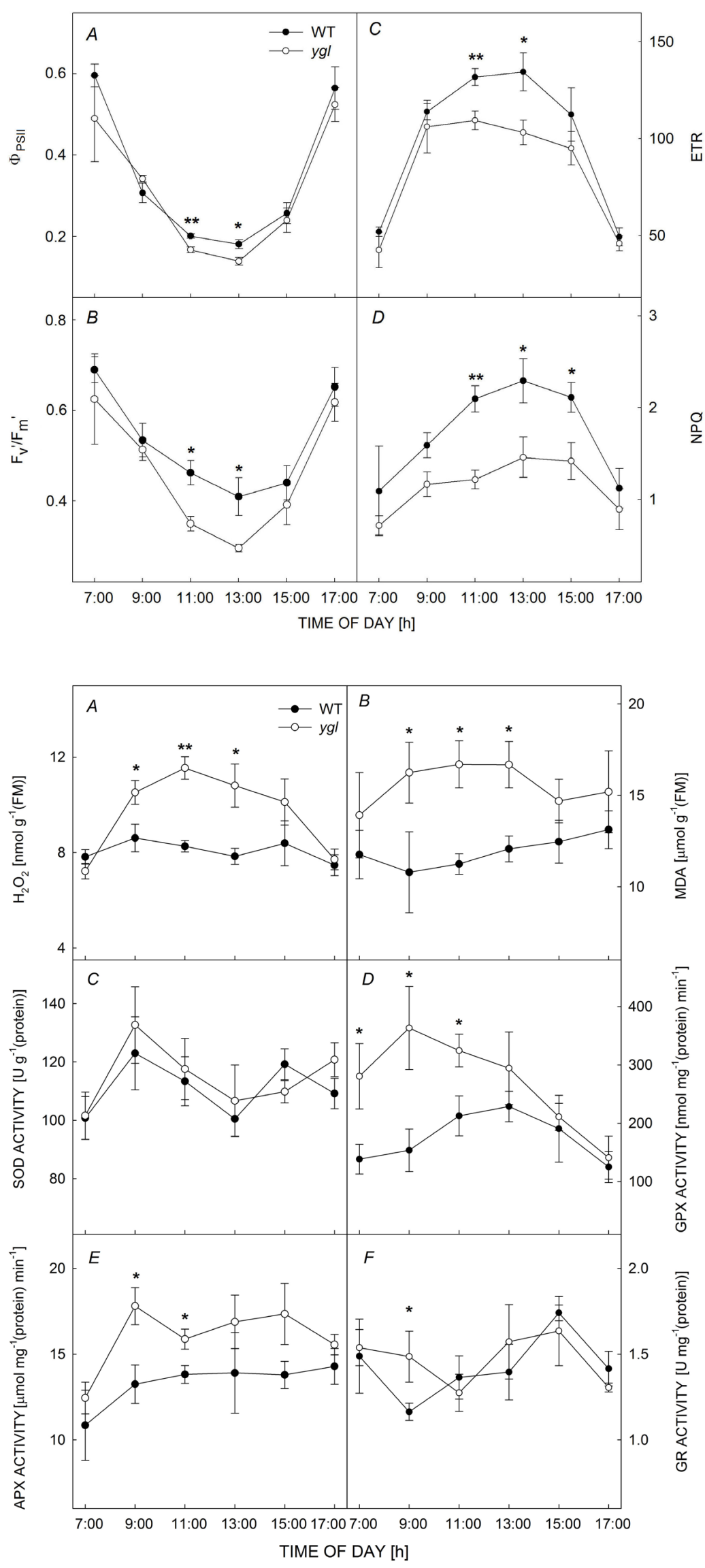

Fig. 5. Diurnal variations in the actual efficiency of PSII photochemistry $\left(\Phi_{\mathrm{PSII}}\right)(A)$, the efficiency of excitation energy capture by open PSII reaction centers $\left(\mathrm{F}_{\mathrm{v}}{ }^{\prime} / \mathrm{F}_{\mathrm{m}}{ }^{\prime}\right)(B)$, electron transport rate (ETR) $(C)$, and nonphotochemical quenching (NPQ) $(D)$ of WT and the $y g l$ mutant of Rosa beggeriana. Values are means $\pm \mathrm{SE}$ with four biological replicates. Means with one $(*)$ or two $(* *)$ asterisks indicate significant differences between WT and the $y g l$ mutant at $P<0.05$ and $P<0.01$, respectively.

Fig. 6. Diurnal variations in $\mathrm{H}_{2} \mathrm{O}_{2}$ concentration $(A)$, malondialdehyde (MDA) concentration $(B)$, superoxide dismutase (SOD) activities $(C)$, guaiacol peroxidase (GPX) activities $(D)$, ascorbate peroxidase (APX) activities $(E)$, and glutathione reductase (GR) activities $(F)$ of WT and the $y g l$ mutant of Rosa beggeriana. Values are means $\pm \mathrm{SE}$ with five biological replicates. Means with one (*) or two (**) asterisks indicate significant differences between WT and the $y g l$ mutant at $P<0.05$ and $P<0.01$, respectively. 


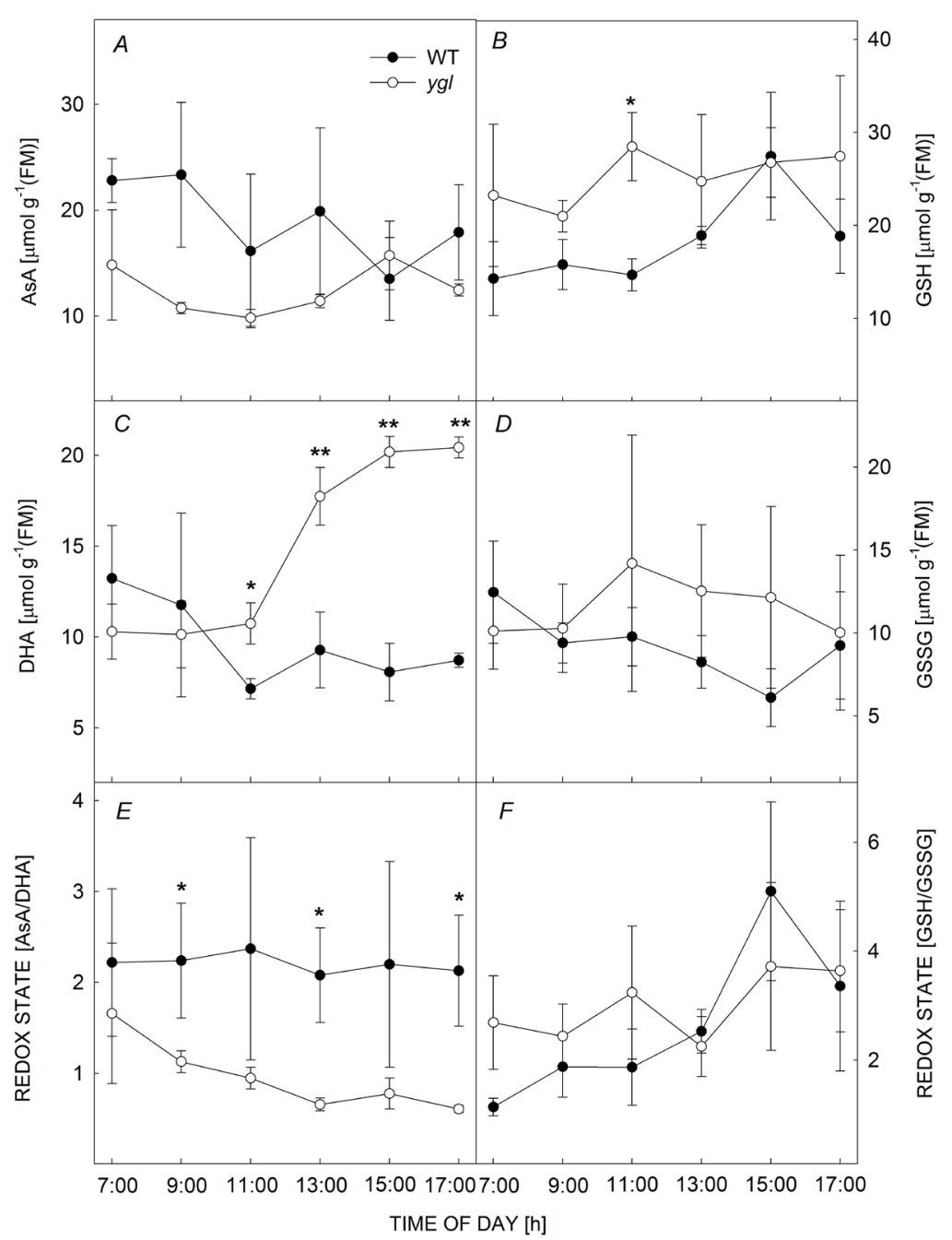

Fig. 7. Diurnal variations in ascorbate (AsA) content $(A)$, dehydroascorbate (DHA) content $(B)$, redox ratio of AsA and DHA $(C)$, reduced glutathione $(\mathrm{GSH})$ content $(D)$, oxidized glutathione (GSSG) content $(E)$, redox ratio of GSH and GSSG $(F)$ of WT and the $y g l$ mutant of Rosa beggeriana. Values are means $\pm \mathrm{SE}$ with five biological replicates. Means with one $(*)$ or two $(* *)$ asterisks indicate significant differences between WT and the $y g l$ mutant at $P<0.05$ and $P<0.01$, respectively.
Schreiber 2001). In this study, the decreased leaf and cuticle thickness together with lower epidermal trichome density in the $y g l$ mutant may have increased the risk of excess light being absorbed, leading to photoinhibition.

Photorespiration is a competitive pathway against $\mathrm{CO}_{2}$ fixation that occurs during photosynthesis in which $\mathrm{O}_{2}$ is assimilated and used to oxidize carbohydrates, with the release of $\mathrm{CO}_{2}$. However, it plays a key role in the protection of the photosynthetic apparatus, avoiding overreduction by consuming the excited energy when $\mathrm{CO}_{2}$ assimilation is restricted (Foyer and Noctor 2000). In the previous studies, the changes in photorespiration had hardly been detected in the leaf color mutants. Our findings on $P_{\mathrm{r}}$ values demonstrated that the stronger photorespiration occurred in the morning than the afternoon in both genotypes. Moreover, the results of $P_{\mathrm{r}} / P_{\mathrm{N}}$ ratios implied that there was more excitation energy allocated to the photorespiration pathway in the $y g l$ mutant than in WT. As described before, the increased allocation of excitation energy to photorespiration can effectively maintain linear photosynthetic electron transport and appropriately utilize excitation energy for $\mathrm{CO}_{2}$ assimilation under photoinhibition, thus alleviating photodamage (Jiang et al. 2006).

Both $\Phi_{\text {PSII }}$ and $F_{\mathrm{v}}{ }^{\prime} / F_{\mathrm{m}}{ }^{\prime}$ reflect the photochemical efficiency status of the PSII reaction center in the light, while ETR represents the relative electron transport rate driven by PSII (Genty et al. 1989). In previous studies, PSII activity was found to vary in $y g l$ mutants. Compared with WT, decreased $\Phi_{\text {PSII }}$ and ETR were detected in the $y g l$ mutants of maize (Zhong et al. 2015), whereas $\Phi_{\text {PSII }}$, $\mathrm{F}_{\mathrm{v}}{ }^{\prime} / \mathrm{F}_{\mathrm{m}}{ }^{\prime}$, and ETR increased in the $y g l$ mutant of rice and foxtail millet (Deng et al. 2014, Li et al. 2016). In our results, significantly lower $\Phi_{\mathrm{PSII}}, \mathrm{F}_{\mathrm{v}}{ }^{\prime} / \mathrm{F}_{\mathrm{m}}{ }^{\prime}$, and ETR at noon in the $y g l$ mutant than in WT suggested that the midday photoinhibition in the mutant was associated with the impaired PSII activity.

NPQ is an indicator that is correlated with excitation energy dissipation and is involved in the protective process of the xanthophyll cycle (Elsheery et al. 2007). Moreover, the DEPS of the xanthophyll cycle is vital for the maintenance of the protective function of thermal dissipation (Demmig-Adams 2003). The enhanced thermal dissipation with improved NPQ and DEPS values had been frequently observed in many Chl-deficient mutants (Falbel et al. 1994, Śtroch et al. 2004, Zhong et al. 2015, Liu et al. 2016). However, NPQ did not change in the $y g l$ mutant of birch (Gang et al. 2019) but decreased in the $y g l$ mutant of foxtail millet (Li et al. 2016). In this study, 
there were significantly lower NPQ values in the $y g l$ mutant than that in WT from 11:00 to 15:00 h (Fig. 5D). The xanthophyll pigments, such as L, N, and V, decreased sharply in the $y g l$ mutant at 7:00 and 13:00 h compared with WT, whereas A, Z, and DEPS were unaltered at noon in both genotypes (Table 2). The results indicated that the mutant tended not to drive the xanthophyll cycle to dissipate excess excitation energy as heat, even when photoinhibition occurred in the mutant.

Impaired thermal dissipation and the enhancement of photorespiration can lead to the overproduction of ROS species in the photosynthetic apparatus. Plants protect against oxidative stress by invoking their antioxidant defense system, consisting of various enzymes and metabolites (Foyer and Noctor 2000). Significantly higher GPX, APX, and GR activities were observed at different times in the morning in the $y g l$ mutant than WT (Fig. $6 D-F$ ), implying that GPX, APX, and GR functioned as ROS scavengers for alleviating oxidative stress in the mutant. Moreover, there were lower AsA/DHA ratios observed in the daytime in the $y g l$ mutant than that in WT (Fig. 7C). The data indicated that the ascorbate-glutathione cycle failed to maintain the redox balance, with ascorbate being highly oxidized in the mutant. As a result, significantly higher $\mathrm{H}_{2} \mathrm{O}_{2}$ and MDA contents were observed from 9:00 to 11:00 h in the $y g l$ plants than WT (Fig. $6 A, B$ ), suggesting that the ROS species sharply accumulated, and ultimately leading to severe membrane lipid peroxidation in the mutant.

In conclusion, there were significant differences in the leaf anatomy, diurnal photosynthesis, and photoprotective strategies in the $y g l$ mutant of Rosa beggeriana in comparison to wild type. The decline of photosynthesis and pigment pools was observed from dawn to noon in both genotypes under high irradiance and air temperature on the sunny summer day. However, there was a severer depression of photosynthesis and pigment contents together with the abnormal chloroplast ultrastructure in the mutant. Moreover, photoinhibition that occurred in the $y g l$ mutant was associated with decreased PSII activity. The anatomical changes with a thinner leaf and cuticle and lower epidermal trichome density in the mutant may have increased the risk of excess light absorption into the chloroplasts. Furthermore, the $y g l$ mutant consumed the excitation energy for photoprotection by improving the photorespiration pathway but did not directly dissipate the excess energy as heat due to the dysfunction of the xanthophyll cycle. To scavenge the harmful ROS generated from the excited energy, the $y g l$ mutant increased antioxidant enzyme activity but failed to maintain the redox balance in the ascorbate-glutathione cycle, ultimately leading to severe membrane lipid peroxidation. We concluded that inhibition of photosynthesis in the $y g l$ mutant of $R$. beggeriana was closely associated with the altered photoprotective strategies that involved in leaf anatomy, photorespiration, thermal dissipation, and antioxidant system.

\section{References}

Alexieva V., Sergiev I., Mapelli S., Karanov E.: The effect of drought and ultraviolet radiation on growth and stress markers in pea and wheat. - Plant Cell Environ. 24: 1337-1344, 2001.

Anderson J.V., Chevone B.I., Hess J.L.: Seasonal variation in the antioxidant system of eastern white pine needles: evidence for thermal dependence. - Plant Physiol. 98: 501-508,1992.

Bendahmane M., Dubois A., Raymond O., Le Bris M.: Genetics and genomics of flower initiation and development in roses. J. Exp. Bot. 64: 847-857, 2013.

Bollivar D.W.: Recent advances in chlorophyll biosynthesis. Photosynth. Res. 90: 173-194, 2006.

Bradford M.M.: A rapid and sensitive method for the quantitation of microgram quantities of protein utilizing the principle of protein-dye binding. - Anal. Biochem. 72: 248-254, 1976.

Carriquí M., Douthe C., Molins A., Flexas J.: Leaf anatomy does not explain apparent short-term responses of mesophyll conductance to light and $\mathrm{CO}_{2}$ in tobacco. - Physiol. Plantarum 165: 604-618, 2019.

Demmig-Adams B.: Linking the xanthophyll cycle with thermal energy dissipation. - Photosynth. Res. 76: 73, 2003.

Deng X.J, Zhang H.Q., Wang Y. et al.: Mapped clone and functional analysis of leaf-color gene $\mathrm{Ygl7}$ in a rice hybrid (Oryza sativa L. ssp. indica). - PLoS ONE 9: e99564, 2014.

Elsheery N.I., Cao K.F.: Gas exchange, chlorophyll fluorescence, and osmotic adjustment in two mango cultivars under drought stress. - Acta Physiol. Plant. 30: 769-777, 2008.

Elsheery N.I., Wilske B., Zhang J.L., Cao K.F.: Seasonal variations in gas exchange and chlorophyll fluorescence in the leaves of five mango cultivars in southern Yunnan, China. J. Hortic. Sci. Biotech. 82: 855-862, 2007.

Falbel T.G., Meehl J.B., Staehelin L.A.: Severity of mutant phenotype in a series of chlorophyll-deficient wheat mutants depends on light intensity and the severity of the block in chlorophyll synthesis. - Plant Physiol. 112: 821-832, 1996.

Falbel T.G., Staehelin L.A., Adams III. W.W.: Analysis of xanthophyll cycle carotenoids and chlorophyll fluorescence in light intensity-dependent chlorophyll-deficient mutants of wheat and barley. - Photosynth. Res. 42: 191-202, 1994.

Farquhar G.D, Sharkey T.D.: Stomatal conductance and photosynthesis. - Ann. Rev. Plant Physio. 33: 317-345, 1982.

Filella I., Peñuelas J.: Altitudinal differences in UV absorbance, UV reflectance and related morphological traits of Quercus ilex and Rhododendron ferrugineum in the Mediterranean region. - Plant Ecol. 145: 157-165, 1999.

Flexas J., Cano F.J., Carriquí M. et al.: $\mathrm{CO}_{2}$ diffusion inside photosynthetic organs. - In: Adams III W., Terashima I. (ed.): The Leaf: A Platform for Performing Photosynthesis. Pp. 163208. Springer, Cham 2018.

Foyer C.H., Noctor G.: Oxygen processing in photosynthesis: regulation and signaling. - New Phytol. 146: 359-388, 2000.

Gang H., Li R., Zhao Y. et al.: Loss of GLK1 transcription factor function reveals new insights in chlorophyll biosynthesis and chloroplast development. - J. Exp. Bot. 70: 3125-3138, 2019.

García-Plazaola J.I., Fernández-Marín B., Ferrio J.P. et al.: Endogenous circadian rhythms in pigment composition induce changes in photochemical efficiency in plant canopies. - Plant Cell Environ. 40: 1153-1162, 2017.

Genty B., Briantais J.M., Baker N.R.: The relationship between quantum yield of photosynthetic electron transport and quenching of chlorophyll fluorescence. - BBA-Gen. Subjects 990: 87-92, 1989.

Gu C.Z., Robertson K.R.: Rosa (Rosaceae). - In: Wu Z.Y., Raven P.H. (ed.): Flora of China. Vol. 9. Pp. 339-381. Science Press, Beijing and Missouri Botanical Garden, St. Louis 2003.

Heath R.L., Packer L.: Photoperoxidation in isolated chloroplasts. I. Kinetics and stoichiometry of fatty acid peroxidation. - Arch. Biochem. Biophys. 125: 189-198, 1968.

Huang S.W., Ge H.: Study on the use of Rosa beggeriana Schrenk 
as a source of cold resistance in rose breeding. - Acta Hortic. Sin. 16: 237-240, 1989. [In Chinese]

Huang S.W., Ge H., Liang L.: A new cultivar of Beggeriana aurea rose by mutant breeding. - North. Hortic. 31: 128-130, 2007. [In Chinese]

Jiang C.D., Gao H.Y., Zou Q. et al.: Leaf orientation, photorespiration and xanthophyll cycle protect young soybean leaves against high irradiance in field. - Environ. Exp. Bot. 55: 87-96, 2006.

Li W., Tang S., Zhang S. et al.: Gene mapping and functional analysis of the novel leaf color gene SiYGL1 in foxtail millet [Setaria italica (L.) P. Beauv]. - Physiol. Plantarum 157: 2437,2016

Liu J., Wang J., Yao X. et al.: Fine mapping and photosynthetic characteristics of the lower chlorophyll $b 1$ mutant in rice (Oryza sativa L.). - Plant Breeding 134: 661-667, 2015.

Liu X., Yu W., Wang G. et al.: Comparative proteomic and physiological analysis reveals the variation mechanisms of leaf coloration and carbon fixation in a xantha mutant of Ginkgo biloba L. - Int. J. Mol. Sci. 17: 1794, 2016.

Osmond C.B.: What is photoinhibition? Some insights from comparisons of shade and sun plants. - In: Baker N.R., Bowyer J.R. (ed.): Photoinhibition of Photosynthesis: From Molecular Mechanisms to the Field. Pp. 1-24. Bios Scientific, Oxford 1994.

Rehem B.C., Almeida A.A.F., Santos I.C. et al.: Photosynthesis, chloroplast ultrastructure, chemical composition and oxidative stress in Theobroma cacao hybrids with the lethal gene Luteus-Pa mutant. - Photosynthetica 49: 127-139, 2011.

Reinbothe C., El Bakkouri M., Buhr F. et al.: Chlorophyll biosynthesis: spotlight on protochlorophyllide reduction. Trends Plant Sci. 15: 614-624, 2010.

Riederer M., Schreiber L.: Protecting against water loss: analysis of the barrier properties of plant cuticles. - J. Exp. Bot. 52: 2023-2032, 2001.
Štroch M., Čajánek M., Kalina J., Špunda V.: Regulation of the excitation energy utilization in the photosynthetic apparatus of chlorina f2 barley mutant grown under different irradiances. J. Photoch. Photobio. B 75: 41-50, 2004.

Thayer S.S., Björkman O.: Leaf xanthopyll content and composition in sun and shade determined by HPLC. Photosynth. Res. 23: 331-343, 1990.

Wang L., Yue C., Cao H. et al.: Biochemical and transcriptome analyses of a novel chlorophyll-deficient chlorina tea plant cultivar. - BMC Plant Biol. 14: 352, 2014.

Wu W., Elsheery N., Wei Q. et al.: Defective etioplasts observed in variegation mutants may reveal the light-independent regulation of white/yellow sectors of Arabidopsis leaves. J. Integr. Plant Biol. 53: 846-857, 2011.

Yang S.H., Li Q.X., Jia R.D. et al.: New rose cultivars Rosa 'Tianxiang', 'Tianshanbaixue', 'Tianshantaoyuan', 'Tianshanzhiguang' and 'Tianshanzhixing'. - Acta Hortic. Sin. 43: 2526-2534, 2016. [In Chinese] doi: 10.16420/j. issn.0513-353x.2015-0637.

Yang S.H., Li S.C., Jia R.D. et al.: Primary construction of a genetic linkage map of Rosa beggeriana 'Aurea' $\times R$. davurica. - Acta Hortic. Sin. 42: 2526-2534, 2015. [In Chinese] doi: 10.16420/j.issn.0513-353x.2015-0382.

Yang S.H., Wang L.J., Li S.H.: Ultraviolet-B irradiation-induced freezing tolerance in relation to antioxidant system in winter wheat (Triticum aestivum L.) leaves. - Environ. Exp. Bot. 60: 300-307, 2007.

Young M.A., Schorr P.: Preface. - In: Young M.A., Schorr P. (ed.): Modern Roses 12: The Comprehensive List of Roses in Cultivation or of Historical or Botanical Importance. Pp. 3. American Rose Society, Shreveport 2007.

Zhong X.M., Sun S.F., Li F.H. et al.: Photosynthesis of a yellowgreen mutant line in maize. - Photosynthetica 53: 499-505, 2015.

(C) The authors. This is an open access article distributed under the terms of the Creative Commons BY-NC-ND Licence. 